\title{
Expressions of Appraisal and Critical Reading
}

\author{
Dr. Fauzia Janjua
}

\begin{abstract}
Associate Professor, Department of English International Islamic University, Islamabad
\end{abstract}

\begin{abstract}
Critical reading does not receive the given text at it's the apparent worth, but engages an intense, relatively deep inspection of the argument for the possible identification of author's intended reasoning. "Reading critically" is a fairly conceptual. "Critical reading" implies teaching the students the way to think while reading. It is described as "learning to evaluate, draw inferences, and arrive at conclusions based on evidence"(Collins, 1989). Teaching critical reading is finding its way into the curriculum of English as ELT pedagogy. Martin \& White (2005) advocates the efficacy of Appraisal system in developing the quality of teaching "critical reading". This study, engaging appraisal framework as a tool to enhance the teaching of reading comprehension skills, experimented 25 advanced level English language learners at International Islamic university, Islamabad. Pre-tests and post-tests in general reading and critical reading were administered in fall 2018. Critical reading tests and observation sheets were developed for the study. The comparison of pre and post evaluation of the group suggested that the use of appraisal system enhance reader's capability to understand interpersonal aspect of written text and facilitate reader's competence to decode semantics of discourse with reference to fact and opinion.
\end{abstract}

Keywords: Critical reading, appraisal system 